\title{
Climate change may alter human physical activity patterns
}

\section{Citation}

Obradovich, Nick, and James H. Fowler. 2017. “Climate Change May Alter Human Physical

Activity Patterns." Nature Human Behaviour 1 (5) (April 24): 0097. doi:10.1038/s41562-017-0097.

\section{Published Version}

doi:10.1038/s41562-017-0097

\section{Permanent link}

http://nrs.harvard.edu/urn-3:HUL.InstRepos:36874928

\section{Terms of Use}

This article was downloaded from Harvard University's DASH repository, and is made available under the terms and conditions applicable to Other Posted Material, as set forth at http:// nrs.harvard.edu/urn-3:HUL.InstRepos:dash.current.terms-of-use\#LAA

\section{Share Your Story}

The Harvard community has made this article openly available.

Please share how this access benefits you. Submit a story.

Accessibility 


\title{
Climate change may alter human physical activity patterns
}

\author{
Nick Obradovich ${ }^{1},{ }^{23}$ James H. Fowler ${ }^{4}$
}

Regular physical activity undergirds healthy human functioning ${ }^{1-3}$. Might climate change -- by modifying the environmental determinants of human physical activity -- alter exercise rates in the future ${ }^{4}$ ? Here we conduct an empirical investigation of the relationship between meteorological conditions, physical activity, and future climate change. Using data on reported participation in recreational physical activity from over 1.9 million United States survey respondents between 2002 and 2012, coupled with daily meteorological data, we show that both cold and acutely hot temperatures as well as precipitation days reduce physical activity. We combine our historical estimates with output from 21 climate models and project the possible physical activity impacts of future climatic changes by 2050 and 2099. Our projection indicates that warming over the course of this century may increase net recreational physical activity in the United States. Activity may

1 Corresponding author.

2 Belfer Center for Science and International Affairs, Kennedy School of Government, Harvard University.

3 Media Lab, Massachusetts Institute of Technology.

4 Departments of Political Science and Medicine, University of California San Diego. 


\section{increase most during the winter in northern states and decline most during the summer in southern states.}

At a physiological level, too little exercise can produce costly health outcomes like obesity $^{1}$, cardiovascular disease ${ }^{3}$ and diabetes ${ }^{2}$, and insufficient physical activity is a leading cause of death in the United States ${ }^{5}$. Sedentary lifestyles are also associated with psychological concerns such as impaired cognitive performance ${ }^{6}$ and a greater risk of clinical depression and anxiety ${ }^{7}$. Human well-being clearly suffers from insufficient physical activity. Yet even in spite of its substantial benefits, people in many countries participate in below-recommended levels of physical activity ${ }^{8}$ and are becoming increasingly sedentary ${ }^{9}$.

Further, external factors like urban and workplace design ${ }^{10}$, social relations ${ }^{11}$, and environmental characteristics shape behaviors regarding when, where, and the extent to which humans are physically active. Of the environmental factors affecting physical activity rates, temperature plays a crucial role ${ }^{12}$. When it is too cold or too hot, adults perform less physical activity, resulting in more sedentary lifestyles. In large part, this reduction is due to the nature of adult physical activity: the vast majority of exercise-related physical activity occurs outdoors ${ }^{13}$. When it is too cold or to hot to go outdoors -- for a walk, a jog, or to garden -- many simply forgo physical activity entirely.

These facts combine to suggest that weather and climate may be significant determinants of behavioral patterns that underlie costly public health crises. Here we report on the effect of meteorological conditions on participation in recreational 
physical activity of over 1.9 million United States residents between 2002 and 2012. Using these data, we examine four questions. First, what weather conditions are most conducive to individual participation in physical activities? Second, do the effects of temperature on physical activity vary by demographic factors like weight and age? Third, how might climate change alter the distribution of physical activity throughout the months of the year in the future? Finally, how might the future impacts of climatic changes on physical activity vary geographically?

To investigate whether outside weather conditions alter the propensity to engage in physical activity, we constructed a dataset of individuals' reported monthly participation in recreational physical activity linked with monthly historical meteorological data. Our individual response data come from the Center for Disease Control and Prevention's Behavioral Risk Factor Surveillance Survey (BRFSS) pooled over the period 2002-2012. Randomly selected respondents answered the below question:

Physical Activity "During the past month, other than your regular job, did you participate in any physical activities or exercises such as running, calisthenics, golf, gardening, or walking for exercise?"

This question includes the most common leisure time physical activities engaged in by adult residents of the United States ${ }^{13}$. Questions from the BRFSS have been assessed for validity ${ }^{14}$ and reliability ${ }^{15}$ and are largely consistent with other healthrelated activity measures including on dimensions of physical activity ${ }^{16}$. Further, 
this specific question is employed in widely cited public health studies relating to physical activity ${ }^{17,18}$.

We combine individual responses to this question -- marked by interview day and geolocated to the city level -- with station-level daily temperature and precipitation data from the National Centers for Environmental Information's Global Historical Climatology Network - Daily (GHCN-D) ${ }^{19}$ as well as humidity and cloud cover data from the National Centers for Environmental Prediction (NCEP) Reanalysis II $\operatorname{project}^{20}$ (see ). Of note, our analysis is robust to the use of gridded daily weather data from the PRISM Climate Group instead (see SI: PRISM Data) ${ }^{21}$. Our theoretical relationship of interest is the effect of meteorological conditions on the probability of being physically active. We empirically model this relationship as:

$$
Y_{i j s t}=f\left(t e m p_{j s t}\right)+Z \eta+\gamma_{t}+v_{j s}+\epsilon_{i j s t}(1)
$$

In this pooled cross-sectional linear probability model fitted via least squares, $i$ indexes individuals, $j$ indexes cities, $s$ indexes seasons, and $t$ indexes calendar days. Our dependent variable $Y_{i j s t}$ is binary and represents whether respondents were physically active over the thirty days prior to their interview day. Our main independent variable, temp $p_{j s t}$, represents the thirty-day average of daily maximum temperatures over the same thirty day window as respondents' reported physical activity. Our relationship of interest is represented by $f\left(\right.$ temp $\left._{j s t}\right)$, which provides separate indicator variables for each $1^{\circ} \mathrm{C}$ monthly aerage maximum temperature bin, allowing for flexible estimation of a non-linear relationship between temperature and physical activity (of note, our results are robust to using one, two, 
and five ${ }^{\circ} \mathrm{C}$ bins, see:SI: Varying Bin Sizes $)^{22,23}$. We omit the $28^{\circ} \mathrm{G} 29^{\circ} \mathrm{C}$ indicator variable, and thus interpret our estimates as the change in probability of being physically active associated with a particular temperature range relative to the $28^{\circ} \mathrm{G}$ $29^{\circ} \mathrm{C}$ baseline.

Further, the $Z \eta$ term in Equation 1 represents an additional set of meteorological variables that include number of precipitation days over the thirty-day window, average temperature range, average cloud cover, and average relative humidity. We include these other meteorological variables as their exclusion might bias our estimates of the effect of included meteorological variables (although the magnitude of the estimates of $f\left(t e m p_{j s t}\right)$ are mostly unaffected by the exclusion of these variables, see: SI: Main Effect)24,25.

Unobserved characteristics may influence participation in physical activity. For example, people may exercise more in cities with better infrastructure or on days when they are more likely to have leisure time. To be sure that geographic and temporal factors like these do not interfere with our estimates, we include $\gamma_{t}$, and $v_{j s}$ in Equation 1. These terms represent calendar date and city-by-season indicator variables that account for unobserved characteristics constant across cities and days as well as seasonal factors that might vary differentially by city ${ }^{26}$. Of note, our results are robust to varying the specification of these controls (see SI: Time and Location Controls). Our empirical identifying assumption, consistent with the literature $25,27-29$, is that meteorological variables are as good as random after conditioning on these fixed effects. The estimated model coefficients can thus be 
interpreted as the effect of meteorological conditions on reports of participation in recreational physical activity24,30,31.

Because our estimation procedure uses exogenous city-level variation in temperature to predict individual-level outcomes, we account for within-city and within-day correlation ${ }^{32}$ by employing heteroskedasticity robust standard errors clustered on both city and day ${ }^{33,34}$. Finally, we omit non-climatic control variables from Equation 1 because of their potential to generate bias -- a phenomenon known as a 'bad control'25,31 -- in our parameter of interest (nonetheless, results are robust to the inclusion of common demographic covariates; see SI: Demographic Controls).

Figure 1 panel (a), which presents the estimates of $f\left(\right.$ temp $\left._{j s t}\right)$ from Equation 1 , indicates the probability of participation in physical activity increases up to $28^{\circ} \mathrm{G}$ $29^{\circ} \mathrm{C}$ and decreases past $36^{\circ} \mathrm{C}$ though effects at higher temperatures are estimated with greater error. Average maximum temperatures around $0^{\circ} \mathrm{C}$ produce a reduction of approximately seven percentage points in the probability of being physically active as compared to the $28^{\circ} \mathrm{G} 29^{\circ} \mathrm{C}$ baseline (coefficient:-7.249, p: , n:1,941,429)). Average maximum temperatures above $40^{\circ} \mathrm{C}$ reduce the probability of physical activity, though the effect is only about one-half as large as the effect of freezing temperatures and is only significant at the $\mathrm{p}=0.10$ level (coefficient: -2.815 , $\mathrm{p}: 0.079$, $\mathrm{n}: 1,941,429)$.

Putting scale to the magnitude of our estimated relationship, $a+2^{\circ} \mathrm{C}$ shift from an average monthly temperature of $26^{\circ} \mathrm{G} 27^{\circ} \mathrm{C}$ to an average of $28^{\circ} \mathrm{C} 9^{\circ} \mathrm{C}$, if extrapolated 
across the current population of the United States, would produce over six million additional person-months of physical activity annually.

However, temperature alone may not fully capture the effect of heat stress on participation in physical activity ${ }^{35-38}$. Heat stress indices, composites between temperature and relative humidity, might indicate that participation in physical activity declines in instances of both high temperature and high humidity ${ }^{39}$. In order to investigate whether heat stress metrics provide substantively different results than temperature alone, we examine the results of estimating:

$$
Y_{i j s t}=f(\text { heat. index } \text { jst })+Z \eta+\gamma_{t}+v_{j s}+\epsilon_{i j s t}(2)
$$

Where we employ the same set of control variables as in Equation 1, but substitute the National Weather Service (NWS) Heat Index $37,40,41$-- our measure of heat stress - for maximum temperature and humidity (of note, the NWS Heat Index mirrors temperature values over the lower portion of its distribution). The results of estimating this equation, presented in Figure 1 panel (b), closely mirror the results of colder maximum temperatures in panel (a) of Figure 1, and we observe no significant decline in physical activity participation at high levels of combined heat and humidity (see SI: Heat Index for the tables associated with this regression). These results, coupled with the insignificance of the marginal effects of relative humidity (panel (d) of Figure 1) indicate that the effect we observe is primarily driven by ambient temperatures (for results using alternative heat stress indices ${ }^{37}$, see SI: Alternative Heat Stress Indices). Further, we observe a small, mostly linear effect of added precipitation days on physical activity participation (panel (c) of 
Figure 1), with greater than 20 days with measurable precipitation in a month producing a reduction of approximately one percentage point in the probability of participation in physical activity (coefficient: -1.144 , p: 0.009, n:1,941,429). We observe no significant relationship between average cloud cover and participation in physical activity.

The above estimates represent an average effect of temperatures on physical activity over the course of a full year across all respondents in our sample. However, because individuals vary in their sensitivity to heat and $\operatorname{cold}^{42}$, we might expect to observe heterogeneous responses to changes in temperature. For example, individuals with higher Body Mass Index (BMI) may experience greater physical stress associated with hot temperatures. Further, older individuals, due to less robust thermoregulation ability ${ }^{43}$, may similarly experience more acute reductions in physical activity due to extreme heat. This leads us to our second question: do the effects of temperature on physical activity vary along important demographic factors like weight and age?

In order to examine whether heavier respondents are more sensitive to temperature, we stratify our sample by BMI and estimate Equation 1 for each subsample $^{28}$. Figure 2, panel (a), shows that the negative effect of temperatures greater than $40^{\circ} \mathrm{C}$ on the probability ofphysical activity is greatest for obese (BMI $>=30$ ) respondents (coefficient: -6.567, p: 0.002, n:466,754). This is over seven times the effect observed among normal weight $(\mathrm{BMI}<25)$ adults (coefficient: -0.866 , p: 0.549, n:711,662) (see SI: Weight Regressions). 
We repeated this procedure to examine whether older respondents are more sensitive to temperature. Figure 2, panel (b), shows that the negative effect of temperatures greater than $40^{\circ} \mathrm{C}$ on the probability of physical activity is greatest for those 65 years of age or older (coefficient: $-7.026, \mathrm{p}$, , n:517,700). This is over four times the effect observed among those under 40 years of age (coefficient: $-1.574, \mathrm{p}$ : $0.569, \mathrm{n}: 456,383)$. Thus, our results suggest that the physical activity rates of both obese and elderly individuals may be most susceptible to higher ambient temperatures.

Our historical data indicate that past temperatures have altered historical physical activity patterns in meaningful ways. Further, climate change is likely to produce positive shifts in monthly temperature distributions in the future ${ }^{44}$ (see Figure 3 , panel (b)). As can be seen in panel (a) of Figure 3, most historical temperatures fall below $28^{\circ} \mathrm{G} 29^{\circ} \mathrm{C}$, the temperature range associated with peak physical activity in our sample. Positive shifts in temperatures below $28^{\circ} \mathrm{G} 29^{\circ} \mathrm{C}$ might increase physical activity while shifts that amplify the incidence of markedly hot temperatures may reduce physical activity. Combining these insights leads us to our third question: how might climate change alter the distribution of physical activity in the United States throughout the months of the year in the future?

To examine this question, we calculate projected average monthly maximum temperatures for 2050 and 2099 from NASA Earth Exchange's (NEX) bias-corrected, statistically downscaled daily maximum temperature projections ${ }^{45}$ drawn from 21 of the CMIP-5 ensemble models ${ }^{46}$ run on the RCP8.5 high emissions or 'business as 
usual' scenario ${ }^{47}$. We couple these predicted temperatures with our historical estimate of the relationship between average maximum temperatures and participation in physical activity -- employing a spline regression model that closely matches the results from Equation 1 -- to calculate a forecast of possible physical activity alterations due to climate change for each month of the year for each city across each downscaled climate model (see SI: Forecast Details).

We define our monthly forecast of the predicted change in physical activity due to climate change by $2050\left(\Delta Y_{m 2050}\right)$ as:

$$
\Delta Y_{m 2050}=\hat{f}\left(\overline{t e m p_{k j m t 2050}}\right)-f\left(\overline{t e m p_{k j m t, 2010}}\right)(3)
$$

and for the effect from 2010 to 2099 ( $\left.\Delta Y_{m 2099}\right)$ as:

$$
\Delta Y_{m 2099}=\hat{f}\left(\overline{\operatorname{temp}_{k j m t 2099}}\right)-\hat{f}\left(\overline{\operatorname{temp}_{k j m t, 2010}}\right)(4)
$$

Where $m$ indexes the month of year, $k$ indexes the 21 specific climate models, $j$ indexes the city, and $t$ indexes the day of year. Further, temp $p_{k j m t}$ is our measure of thirty-day average maximum temperatures, as calculated in Equation 1 and $f(\quad)$ represents the fitted spline function from our main forecast model (see SI: Forecast Models). Importantly, this estimation procedure allows us to incorporate uncertainty regarding the underlying climatic forecasts into our physical activity predictions ${ }^{27}$. It also allows us to account for estimation uncertainty in our model of physical activity.

Figure 3 panels (c) and (d) plot our monthly forecast results for 2050 and 2099, respectively. The bar for each month represents an average prediction across each 
of the 21 climate models, across each of the cities in our analysis, and across the days in that month. The error lines on these bars represent the full range of these monthly estimates across the 21 downscaled climate models and incorporate the 95\% confidence interval of the estimated historical relationship between temperature and physical activity. As can be seen in these figures, the likely temperature changes produced by climate change may most increase physical activity in traditionally cooler months of the year. In the months of June, July, and August, climate change by 2099 may reduce physical activity on net. Taking a yearly sum of our monthly average predictions across the United States, we project that climate change may cause approximately 40 additional physically active personmonths per 1,000 individuals on net by 2050 and approximately 70 additional person-months per 1,000 individuals on net by 2099 .

Additionally, temperature alterations associated with climate change -- and thus the potential impacts of climate change on physical activity -- are likely to vary spatially across the United States. To investigate the geographic distribution of potential modifications in physical activity due to climate change, we take the ensemble average of the 21 NEX downscaled climate models for each of 2010, 2050, and 2099. We then take the monthly average of maximum temperatures for each approximately $25 \mathrm{~km}$ x $25 \mathrm{~km}$ grid cell in the continental U.S. in each year. For the 2050 forecast, we assign to each grid cell the predicted net monthly difference in physical activity between 2010 and 2050. For the 2099 forecast we assign to each grid cell the predicted net monthly difference in physical activity between 2010 and 2099. Figure 4 shows that most areas of the United States may see net increases in 
physical activity as a result of climate change this century, while southernmost areas may experience some net decreases in physical activity (see SI: Grid Cell Forecast).

Finally, smoothing geographic forecasts across the full year (as in Figure 4) masks the temporal heterogeneity associated with our physical activity forecasts. Figure 5 plots the geographic forecasts for each month in the years 2050 and 2099 respectively. Future winter months, especially in northern areas of the US may see the greatest increases in physical activity rates, while future summer months, particularly in southern areas of the US may see net decreases in physical activity rates.

Historical data demonstrates a robust link between temperature and human physical activity. The effects of cold historical temperatures on reduced participation in physical activity are highly statistically significant and substantively large in magnitude. Moreover, in both our city-level and geographic forecasts, we predict that much of the United States will experience increased physical activity due to future climatic changes. These increases occur primarily during cooler months of the year, with summer months -- especially in southern areas of the US -likely seeing potential declines in future physical activity.

There are several considerations important to the interpretation of these results. First, while we have data on millions of individuals' reported monthly participation in physical activity, optimal data would also contain measurements of each individual's participation in daily physical activity and the intensity of such activity. Second, because respondents are geolocated to the city-level, measurement error 
may exist between the temperatures observed at weather stations and the temperatures respondents actually experienced, possibly attenuating the magnitude of our estimates ${ }^{48}$. Third, our analysis is conducted on a randomly sampled, pooled cross section of respondents. An ideal source of data would track the same individuals over time to enable controlling for individual-specific characteristics. Fourth, our data are restricted to observations from one country with a temperate climate. It is critical to repeat this analysis where possible in countries with warmer average climates ${ }^{49}$ and lower prevalence of air conditioning 50 , as they may see net reductions in physical activity due to climate change. Fifth, in this analysis we focus on recreational physical activities. However, because occupational physical activity may be less discretionary, the effects of climate change on occupational physical activity deserve further scrutiny ${ }^{38,51}$. Sixth, because the hottest historical regions in our data also tend to have lower humidity, our analysis may understate the potential for amplified future levels of heat stress to reduce physical activity. Future studies should investigate this question. Finally, it is possible that humans may adapt technologically and physiologically to warmer climates with behaviors not seen in the historical data $42,52,53$.

Ultimately, most of climate change's social impacts are likely to be negative ${ }^{30}$. Climate change may reduce economic output ${ }^{24}$, amplify rates of conflict ${ }^{31}$, produce psychological distress ${ }^{54}$, increase exposure to the social effects of drought ${ }^{55}$, and increase heat-related mortality and morbidity 56-61, among other ills. However, climatic changes are unlikely to be uniformly costly to society, and it is important to investigate both costs and benefits. Here we uncover a possible beneficial impact of 
climate change for the United States. If observed temperature-activity relationships from the recent past persist, further climate change may increase nationwide net participation in recreational physical activity during many months of the year, in turn magnifying many of the physiological and psychological benefits of exercise. However, adaptations to changing temperature distributions or interactions with potential pernicious effects of climate change ${ }^{30}-$ - like increased stress and anxiety ${ }^{54}$ -- may counteract these effects. The more we know about the full range of potential climate impacts, the better we will be able to prepare for what is likely to be humanity's greatest challenge in the 21st Century.

\section{Correspondence}

Correspondence and requests for materials should be addressed to N.O.

\section{Acknowledgements}

We thank the San Diego Supercomputer Center for their assistance. N.O. was supported during the course of manuscript preparation by the Frontiers of Innovation Fellowship from the University of California San Diego, the Belfer Center for Science and International Affairs at the Harvard Kennedy School, and the MIT Media Lab. The funders had no role in study design, data collection and analysis, decision to publish, or preparation of the manuscript. 


\section{Author contributions}

N.O. conceived of the research question, constructed and analyzed the historical data, conducted the forecast, and compiled the supplementary information. N.O. and J.H.F. developed figures and drafted the manuscript.

\section{Competing interests}

The authors declare they have no competing interests.

\section{Data availability}

Replication data can be accessed via Harvard's Dataverse (doi:10.7910/DVN/SGQEZP).

\section{Code availability}

Replication code can be accessed via Harvard's Dataverse (doi:10.7910/DVN/SGQEZP).

\section{References}

1. Hill, J. O. \& Peters, J. C. Environmental contributions to the obesity epidemic.

Science 280, 1371-1374 (1998).

2. Sigal, R. J., Kenny, G. P., Wasserman, D. H., Castaneda-Sceppa, C. \& White, R. D. Physical activity/exercise and type 2 diabetes a consensus statement from the American Diabetes Association. Diabetes Care 29, 1433-1438 (2006). 
3. Shiroma, E. J. \& Lee, I.-M. Physical activity and cardiovascular health lessons learned from epidemiological studies across age, gender, and race/ethnicity. Circulation 122, 743-752 (2010).

4. Stamatakis, E., Nnoaham, K., Foste, C. \& Scarboroug, P. The influence of global heating on discretionary physical activity: An important and overlooked consequence of climate change. J. Phys. Act. Health 10, 765-768 (2013).

5. Mokdad, A. H., Marks, J. S., Stroup, D. F. \& Gerberding, J. L. Actual causes of death in the United States, 2000. JAMA 291, 1238-1245 (2004).

6. Hillman, C. H., Erickson, K. I. \& Kramer, A. F. Be smart, exercise your heart: Exercise effects on brain and cognition. Nature Reviews Neuroscience 9, 58-65 (2008).

7. Teychenne, M., Ball, K. \& Salmon, J. Physical activity and likelihood of depression in adults: A review. Preventive Medicine 46, 397-411 (2008).

8. Haskell, W. L. et al. Physical activity and public health: Updated recommendation for adults from the American College of Sports Medicine and the American Heart Association. Circulation 116, 1081 (2007).

9. Brownson, R. C., Boehmer, T. K. \& Luke, D. A. Declining rates of physical activity in the United States: What are the contributors? Annu. Rev. Public Health 26, 421-443 (2005). 
10. Brownson, R. C., Baker, E. A., Housemann, R. A., Brennan, L. K. \& Bacak, S. J. Environmental and policy determinants of physical activity in the United States. American Journal of Public Health 91, 1995-2003 (2001).

11. Giles-Corti, B. \& Donovan, R. J. The relative influence of individual, social and physical environment determinants of physical activity. Social Science \& Medicine 54, 1793-1812 (2002).

12. Tucker, P. \& Gilliland, J. The effect of season and weather on physical activity: A systematic review. Public Health 121, 909-922 (2007).

13. Dannenberg, A. L., Keller, J. B., Wilson, P. W. \& Castelli, W. P. Leisure time physical activity in the Framingham Offspring Study description, seasonal variation, and risk factor correlates. American Journal of Epidemiology 129, 76-88 (1989).

14. Oswald, A. J. \& Wu, S. Objective confirmation of subjective measures of human well-being: Evidence from the USA. Science 327, 576-579 (2010).

15. Nelson, D. E., Holtzman, D., Bolen, J., Stanwyck, C. A. \& Mack, K. A. Reliability and validity of measures from the Behavioral Risk Factor Surveillance System (BRFSS). Sozial-und Praventivmedizin 46, S3-42 (2000).

16. Yore, M. M. et al. Reliability and validity of the instrument used in BRFSS to assess physical activity. Medicine and Science in Sports and Exercise 39, 1267-1274 (2007). 
17. Siegel, P. Z., Brackbill, R. M. \& Heath, G. W. The epidemiology of walking for exercise: Implications for promoting activity among sedentary groups. American Journal of Public Health 85, 706-710 (1995).

18. Evenson, K. R., Herring, A. H. \& Huston, S. L. Evaluating change in physical activity with the building of a multi-use trail. American Journal of Preventive Medicine 28, 177-185 (2005).

19. Menne, M. J., Durre, I., Vose, R. S., Gleason, B. E. \& Houston, T. G. An overview of the Global Historical Climatology Network-daily database. Journal of Atmospheric and Oceanic Technology 29, 897-910 (2012).

20. Kanamitsu, M. et al. NCEP-DOE AMIP-II reanalysis (R-2). Bulletin of the American Meteorological Society 83, (2002).

21. Di Luzio, M., Johnson, G. L., Daly, C., Eischeid, J. K. \& Arnold, J. G. Constructing retrospective gridded daily precipitation and temperature datasets for the conterminous United States. Journal of Applied Meteorology and Climatology 47, 475-497 (2008).

22. Deschênes, 0. \& Greenstone, M. Climate change, mortality, and adaptation: Evidence from annual fluctuations in weather in the US. American Economic Journal: Applied Economics 3, 152-185 (2011).

23. Graff Zivin, J. S. \& Neidell, M. Temperature and the allocation of time: Implications for climate change. Journal of Labor Economics 32, 1-26 (2014). 
24. Burke, M., Hsiang, S. \& Miguel, E. Global non-linear effect of temperature on economic production. Nature 527, 235-235 (2015).

25. Hsiang, S. Climate econometrics. Annual Review of Resource Economics 8, 43-75 (2016).

26. Wooldridge, J. M. Econometric analysis of cross section and panel data. (MIT press, 2010).

27. Auffhammer, M., Hsiang, S. M., Schlenker, W. \& Sobel, A. Using weather data and climate model output in economic analyses of climate change. Review of Environmental Economics and Policy ret016 (2013).

28. Dell, M., Jones, B. F. \& Olken, B. A. What do we learn from the weather? The new climate-economy literature. Journal of Economic Literature 52, 740-798 (2014).

29. Obradovich, N. Climate change may speed democratic turnover. Climatic Change $1-13(2016)$.

30. Carleton, T. A. \& Hsiang, S. M. Social and economic impacts of climate. Science 353, aad9837 (2016).

31. Hsiang, S. M., Burke, M. \& Miguel, E. Quantifying the influence of climate on human conflict. Science 341, 1235367 (2013).

32. Moulton, B. R. An illustration of a pitfall in estimating the effects of aggregate variables on micro units. The Review of Economics and Statistics 334-338 (1990). 
33. Cameron, A. C., Gelbach, J. B. \& Miller, D. L. Robust inference with multiway clustering. Journal of Business \& Economic Statistics 29, (2011).

34. Stock, J. H. \& Watson, M. W. Heteroskedasticity-robust standard errors for fixed effects panel data regression. Econometrica 76, 155-174 (2008).

35. Haldane, J. The influence of high air temperatures no. i. Journal of Hygiene 5, 494-513 (1905).

36. Simon, H. B. Hyperthermia. New England Journal of Medicine 329, 483-487 (1993).

37. Buzan, J., Oleson, K. \& Huber, M. Implementation and comparison of a suite of heat stress metrics within the community land model version 4.5. Geoscientific Model Development 8, 151 (2015).

38. Kjellstrom, T. et al. Heat, human performance, and occupational health: A key issue for the assessment of global climate change impacts. Annual review of public health 37, 97-112 (2016).

39. Minard, D., Belding, H. S. \& Kingston, J. R. Prevention of heat casualties. Journal of the American Medical Association 165, 1813-1818 (1957).

40. Steadman, R. G. The assessment of sultriness. part I: A temperature-humidity index based on human physiology and clothing science. Journal of Applied Meteorology 18, 861-873 (1979). 
41. Rothfusz, L. P. The heat index equation (or, more than you ever wanted to know about heat index). Fort Worth, Texas: National Oceanic and Atmospheric Administration, National Weather Service, Office of Meteorology 9023, (1990).

42. Périard, J. D., Travers, G. J., Racinais, S. \& Sawka, M. N. Cardiovascular adaptations supporting human exercise-heat acclimation. Autonomic Neuroscience 196, 52-62 (2016).

43. Van Someren, E. J., Raymann, R. J., Scherder, E. J., Daanen, H. A. \& Swaab, D. F. Circadian and age-related modulation of thermoreception and temperature regulation: Mechanisms and functional implications. Ageing Research Reviews 1, 721-778 (2002).

44. Seneviratne, S. I., Donat, M. G., Mueller, B. \& Alexander, L. V. No pause in the increase of hot temperature extremes. Nature Climate Change 4, 161-163 (2014).

45. Thrasher, B., Maurer, E. P., McKellar, C. \& Duffy, P. Technical note: Bias correcting climate model simulated daily temperature extremes with quantile mapping. Hydrology and Earth System Sciences 16, 3309-3314 (2012).

46. Taylor, K. E., Stouffer, R. J. \& Meehl, G. A. An overview of CMIP5 and the experiment design. Bulletin of the American Meteorological Society 93, 485-498 (2012).

47. Riahi, K. et al. RCP 8.5 - a scenario of comparatively high greenhouse gas emissions. Climatic Change 109, 33-57 (2011). 
48. Hausman, J. Mismeasured variables in econometric analysis: Problems from the right and problems from the left. Journal of Economic Perspectives 57-67 (2001).

49. Gasparrini, A. et al. Changes in susceptibility to heat during the summer: A multicountry analysis. American journal of epidemiology 183, 1027-1036 (2016).

50. Davis, L. W. \& Gertler, P. J. Contribution of air conditioning adoption to future energy use under global warming. Proceedings of the National Academy of Sciences 112, 5962-5967 (2015).

51. Parsons, K. Occupational health impacts of climate change: Current and future iSO standards for the assessment of heat stress. Industrial health 51, 86 (2013).

52. Sawka, M. N., Leon, L. R., Montain, S. J. \& Sonna, L. A. Integrated physiological mechanisms of exercise performance, adaptation, and maladaptation to heat stress. Comprehensive Physiology (2011).

53. Castellani, J. W. \& Tipton, M. J. Cold stress effects on exposure tolerance and exercise performance. Comprehensive Physiology (2016).

54. Doherty, T. J. \& Clayton, S. The psychological impacts of global climate change. American Psychologist 66, 265 (2011).

55. Dai, A. Drought under global warming: A review. Wiley Interdisciplinary Reviews: Climate Change 2, 45-65 (2011). 
56. Basu, R. \& Samet, J. M. Relation between elevated ambient temperature and mortality: A review of the epidemiologic evidence. Epidemiologic reviews 24, 190$202(2002)$.

57. Deschenes, 0. Temperature, human health, and adaptation: A review of the empirical literature. Energy Economics 46, 606-619 (2014).

58. Hajat, S., Armstrong, B. G., Gouveia, N. \& Wilkinson, P. Mortality displacement of heat-related deaths: A comparison of Delhi, Sao Paulo, and London. Epidemiology 16, 613-620 (2005).

59. Gething, P. W. et al. Climate change and the global malaria recession. Nature 465, $342-345$ (2010).

60. Guo, Y. et al. Global variation in the effects of ambient temperature on mortality: A systematic evaluation. Epidemiology (Cambridge, Mass.) 25, 781 (2014).

61. Shi, L., Kloog, I., Zanobetti, A., Liu, P. \& Schwartz, J. D. Impacts of temperature and its variability on mortality in New England. Nature climate change 5, 988-991 (2015). 
Figure 1 Recreational physical activity peaks at higher temperatures and heat index values and declines with higher numbers of precipitation days. Panel (a) draws from the estimation of the linear probability model in Equation 1 on over 1.9 million respondents' reported monthly participation in physical activities between 2002 and 2012. It plots the predicted probability of physical activity associated with each maximum temperature bin. Participation in physical activities increases up to $28{ }^{\circ} \mathrm{G} 29^{\circ} \mathrm{C}(8284 \mathrm{~F})$ and begins to decline past that point, though the effects of hotter temperatures are estimated with higher uncertainty. Panel (b) plots the marginal effects of the National Weather Service Heat Index on the probability of physical activity participation. The effects of colder values of the Heat Index closely mirrors the effects of colder maximum temperatures. Panel (c) plots the effect of monthly days with measurable precipitation on physical activity. Added precipitation days linearly decrease the probability of participation in physical activity, though the marginal effects are notably smaller than they are for temperature or heat stress. Panel (d) indicates there is no independent effect of relative humidity on engagement in physical activities. Points in each panel represent the mean percentage of respondents who were physically active in the past month for each bin of the respective meteorological variable. Shaded error bounds represent 95\% confidence intervals. 
Figure 2 Heat most reduces participation in physical activity among the obese

and the elderly. Panel (a) depicts the marginal effects from Equation 1 run on samples stratified by Body Mass Index (BMI). The observed effects of temperature are similar in normal weight and overweight individuals. Excessive heat (above $40^{\circ} \mathrm{C}$ ) most reduces physical activity in obese individuals. Panel (b) displays the marginal effects associated with splitting the sample by age. Younger and middle aged adults have similar responses to hot temperatures, while elderly individuals most reduce their participation in physical activity in response to excessive heat (see SI: Weight Regressions and SI: Age Regressions). 
Figure 3 Climate change may alter temporal patterns of physical activity. Panel

(a) plots the historical the distribution of 2002-2012 average monthly maximum temperatures from our sample. Approximately $80 \%$ of this distribution falls below $28^{\circ} \mathrm{G} 29^{\circ} \mathrm{C}$, the temperature range associated with peak historical physical activity. Panel (b) presents monthly average maximum temperatures calculated from 21 downscaled CMIP5 climate models for the cities in our sample in 2010, 2050, and 2099. Maximum temperatures increase by 2050 and 2099 as compared to the baseline of 2010. Bars in panel (c) depict the mean city-level forecast for the impact of climate change by 2050 on monthly physical activity per 1,000 individuals. Bars in panel (d) display the same forecast for 2099. In both panels (c) and (d), physical activity is predicted to increase most in cooler months of the year and decline in summer months. To incorporate downscaled climate model uncertainty, error bars in panels (c) and (d) represent the range of monthly predictions across the ensemble of climate models and incorporate estimation uncertainty from our model of physical activity ${ }^{27}$. 
Figure 4 Climate change may alter physical activity rates spatially throughout

the US This figure presents the $25 \mathrm{~km} \times 25 \mathrm{~km}$ grid cell forecasts of the potential impact of climate change on annual person-months of physical activity per 1,000 individuals. In this figure, downscaled climatic model data are averaged across the 21 models in the ensemble and then coupled with our historical model parameters to produce an estimated change in physically active person-months in each geographic location for the periods of 2050 and 2099. Areas of northern United States -- where non-summer temperatures are currently coldest -- may experience the largest future increase in net physical activity. The southernmost extremes of the US, cities like Phoenix, Arizona, may experience net reductions in physical activity in the future. 
Figure 5 Climate change may increase physical activity most in cooler months in the northern U.S. and reduce it most in summer months in the southern U.S. This figure presents the $25 \mathrm{~km} \times 25 \mathrm{~km}$ grid cell forecasts of the potential impact of climate change on monthly person-months of physical activity per 1,000 individuals. In this figure, downscaled climatic model data are averaged across the 21 models in the ensemble and then coupled with our historical model parameters to produce an estimated change in physically active person-months in each geographic location for the months of 2050 and 2099. Areas of northern United States -- where non-summer temperatures are currently coldest -- may experience the largest future increase in net physical activity, especially in cooler months of the year. The southern US may experience net reductions in physical activity, especially during future summer months. 